\title{
Study of Sectional Change after Gravel Beach Maintenance Wang Zhenchuan ${ }^{1, a}$, Shangguan ZiChang ${ }^{2, b^{*}}$, Jin Tao ${ }^{3}$ ${ }^{1,2,3}$ College of Ocean and Civil Engineering, Dalian Ocean University, Dalian, Liaoning, China

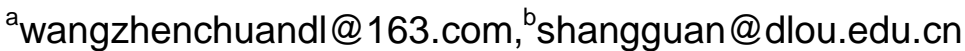

Keywords: beach maintenance; fill stone restoration; sectional change; effect of the ripped-rock embankment

\begin{abstract}
The phenomenon of coastal erosion in our country is becoming more and more common in recent years, as people's attention to coastal erosion issues, scholars and experts have proposed all kinds of beach protection policies and structural measures and put them into practice. In order to study changes of profile after beach maintenance, we take Yingkou Hebe gravel beach as an example, using the normal integral model to do the dimensional gravel beach test. The experiment proved that gravel beach with filling stone at different return periods after wave effect can reach an unstable equilibrium cross-sectional form, with the longer duration of the wave's action, the whole beach profile was showing an erosion form: seaward from the shore, formed a certain sand deposit on the berm platform and slowly goes to the shore, from the middle of the slope to the berm edge has the biggest erosion, easy to form a bunker, the erosion to the lower part of the slope was smaller and gradually reduce towards the sea. Additional riprap in front of seashores has little effect on the change of beach profile.
\end{abstract}

\section{Introduction}

Beach maintenance has become the main measures of prevention and control of coastal erosion. Many experimental studies abroad, especially on evolution of the beach sectional evolution. Foreign institutions had carried out experimental study for underwater section ${ }^{[1]}$ under the conditions of different wave and water level and the development of the sand dunes deformation, sediment migration since 1955. In recent years, domestic scholars has also carried out the experimental study of different size, Feng Weibing, Yang Yanxiong and Zou Zhili ${ }^{[2]}$ conducted independently two-dimensional sandy beach morphological research, through a series of experimental analysis the artificial beach equilibrium profile morphological characteristics under the influence of different sediment particle sizes and different return periods and wave direction. These experiments are all analyzing the beach evolution law, the beneficial attempt to optimize the design of the artificial beach Systematic, targeted research on beach maintenance in China is still less, reasonable spirit of scientific experiments should be carried out to advocate, from the physical and numerical experiments two-pronged approach to enhance the ability to predict beach nourishment project to improve science and reliability engineering.

Hebe gravel beach at Yingkou Liaoning Province is located in the south coast side, $66 \mathrm{~km}$ away from Yingkou, $1000 \mathrm{~m}$ from Liaoning coastal road. Geographical coordinates of South seaward side is: latitude $40^{\circ} 07$ '07 " $40^{\circ} 07$ '09"; East longitude $121^{\circ} 58$ '50 " $121^{\circ} 58$ '58".

According to Zhuang Zhenye's ${ }^{[3]}$ survey of bohai bay and wave frequency statistics of all levels, frequency of wave's height less than $0.5 \mathrm{~m}$ is $71 \%$; frequency of wave height than or equal to $0.5 \mathrm{~m}$ but less than $1.5 \mathrm{~m}$ is $28 \%$; frequency of wave's height more or equal to $1.5 \mathrm{~m}$ but less than $3.0 \mathrm{~m}$ was $1 \%$. Thus, waves rarely appears, light waves in most of the time. 


\section{Selection of Similar Models}

Zhu Jin-long ${ }^{[4]}$ and others' research shows that the main factors of scouring-erosion variation of the beach profile is dynamic and sediment movement under the action of waves, therefore, to properly simulate scouring-erosion variation must guarantee the beach wave and the sediment movement similar.

In view of Yingkou Hebe is composed of gravel, so this experiment uses the gravity similarity criterion, the normal model. Considering test equipment and 'the relevant provisions of "wave model test procedures' and technical requirements and other factors to determine the model geometry scale is $1: 20$.

\section{Research Methods}

The test is normal physical model tests, according to the terrain built by mathematical model, select the beach in the middle part of the cross-sectional pilot to study, extract the original terrain section for wave simulations. After the original terrain finished building, with cement plaster to make it smooth, no distortion, much closer to the original terrain. As the physical model test results of the simulation are gravel beach under wave action, so it's based on sample stone as filled material, we use natural sand that their median diameter are $\mathrm{D}=1.25,2.5,5 \mathrm{~mm}$ in proportion of a $3: 4: 3$ mixture. Sand slope terrain is made by the sand filling degree of 1: 17, 1: 5.6.

According to "Preliminary design phase of the project of Yingkou, Liaoning Province Hebe observation and drone base station" Design of Yingkou Hebe south coast side high and low water level, extreme high and low water level are:((local theoretical datum)

Design high water level $4.00 \mathrm{~m}$ (1.962)

Design low water level 0.24 m (-1.798)

Extreme high water level $5.14 \mathrm{~m}$ (3.102)

Extremely low water level $-1.69 \mathrm{~m}(-3.728) \quad$ Note: () for 85 yellow sea height conversion system.

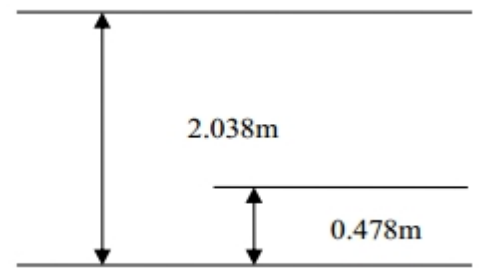

figure 1 relationship between each plane

Wave conditions are according to the MIKE21 BW module calculates, comparative results, $\mathrm{W}$ to the biggest waves, so take the direction waves of $\mathrm{W}$ as the wave calculation's condition. In the following table: 
Table 1 Experimental westward direction, significant wave height of submerged breakwater at the harbor design

\begin{tabular}{llll}
\hline $\begin{array}{l}\text { the water level } \\
\text { (theoretical depth) }\end{array}$ & $\begin{array}{l}\text { return period } \\
\text { (year) }\end{array}$ & $\begin{array}{l}\text { significant } \\
\text { wave } \\
\text { height }(\mathrm{m})\end{array}$ & period (s) \\
\hline \multirow{4}{*}{5.14} & 2 & 0.97 & 6.4 \\
& 5 & 1.50 & 8.3 \\
& 10 & 1.72 & 8.7 \\
& 25 & 1.95 & 9.1 \\
\hline 4.0 & 2 & 0.94 & 6.4 \\
& 5 & 1.42 & 8.3 \\
& 10 & 1.65 & 8.7 \\
\hline
\end{tabular}

Specific test procedure is as follows: by Ma Guizhi ${ }^{[5,6]}$ proposed test method, The corresponding experimental wave parameters was calibrated, and the study of Shen Jianping ${ }^{[7]}$ and others the discussion of the evolution process of the underwater profile, We design high water level in the water level of the case, according to the different waves in order to reproduce the effect of the terrain, we design high water level in the water level of the case, according to the different waves in order to reproduce the effect of the terrain, a simulation effect every six minutes, each case simulate three or four times, each time not recover terrain after simulation completed, till the water in the sink after static simulation, according to the ascending wave cycle. After the end of the cycle, to restore the original terrain, additional riprap in front of seashores, repeat the test procedure before.

\section{Results and Analysis}

\section{Study of Different Return Periods Wave Flushing on Gravel Beach.}

Beach balanced cross section can form an important research direction of the beach. We can know from the discuss of the significance of model parameters written by Li Zhiqiang ${ }^{[8]}$ and others , in the model experiment, whether the subject of the same cross-sectional wave action after a certain time gravel beach profile can form balanced cross section were studied in different time. In the design of high-level, for each return period waves, make its effect on profile after six to seven minutes intervals to a section topography measurement, measuring three to four groups, to a smaller cross-sectional topography changes, and replaced next group return period waves above experiment was repeated steps. During this time without having to restore the terrain, only need to records section of terrain changes.

\section{Changes of profile model under the wave of two years' reproduction.}

The two-year return period waves, for example, can be seen from the figure, six minutes after two years' return period waves' action, sectional topography change is not significant, over the berm platform basically have no change, in the (34 $\mathrm{m}$ from slope to the shore) below the berm platform form a small deposit of gravel, shown in Figure 2 has a smaller effect on erosion slopes. Gravel stacked body 12 min after the wave action is about 1.5 times than the reaction time of six minutes, the degree of erosion on the slope begins to increase and forming an obvious bunkers as shown in figure 3. Gravel stacked body $18 \mathrm{~min}$ after the wave action is about 1.5 times than the reaction time of six 
minutes, the bunker on the slopes continue to increase in Figure 2 4.
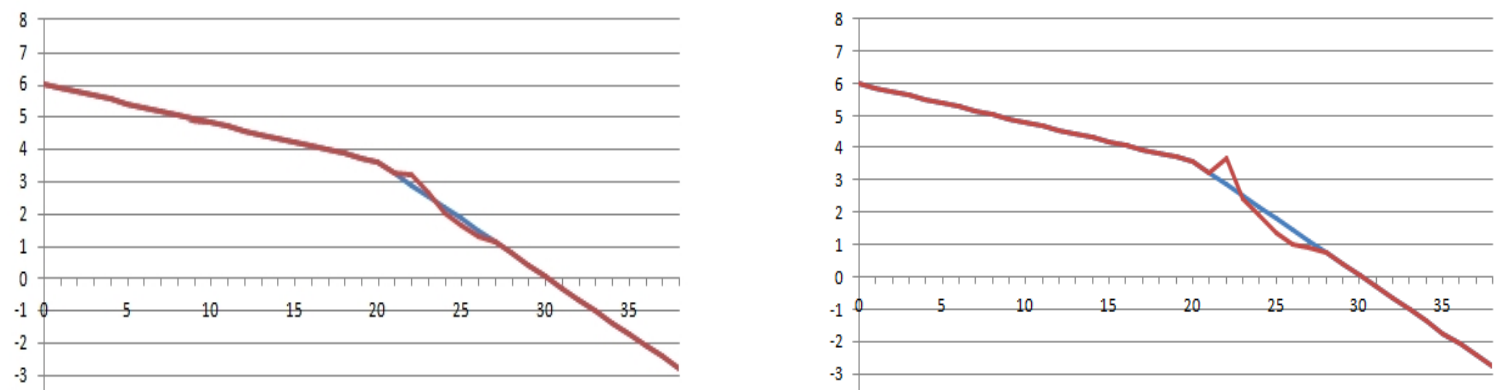

Figure 2, 3 six minutes after the first and second wave of two years'reproduction

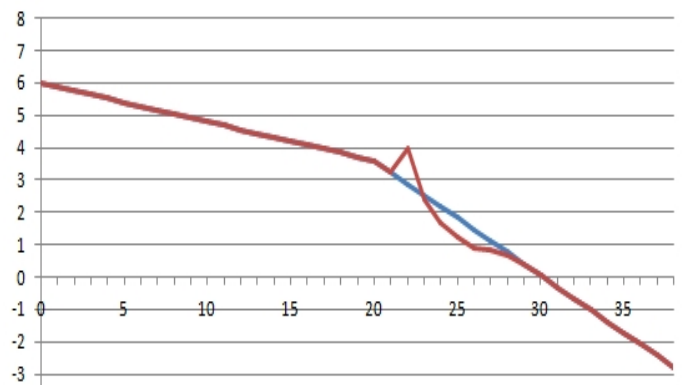

Figure 4 six minutes after the third wave of two years' reproduction

In short, the whole beach profile platform towards seaward berm was washed morphology, wash degree is increasing with the increase of time, the role of the maximum scour every six minutes sequentially is about $22 \mathrm{~cm}$ (converted into a prototype), $46 \mathrm{~cm}, 52 \mathrm{~cm}$, and mostly maximum slope erosion occurred in the vicinity of $26 \mathrm{~m}$.

From slope to shore about 30-34 m, cross-sectional has some siltation and sedimentation height is small at $6 \mathrm{~min}, 12 \mathrm{~min}$ and $18 \mathrm{~min}$ deposition height is basically the same. Overall, broken section of the waves 18-34 m from slope to shore (which measure figure near the point of Figure 21-29), due to wave breaking effect, This presents a hollowed-out gravel sand state, which portion is hollowed out with the sand as part of the wave receded, another portion was washed to the above, at the top stacking piles of sand, therefore the sands presents a moving upward trend, and with the increase in the number of tests, the sand will be gradually increased, and there is also has a moving upward trend. Wave continued for some time after $18 \mathrm{~min}$, found that the degree of scouring sand didn't change much, while siltation and sand berm slopes below the platform are still increasing, but the degree of change is greatly reduced than before, the basic cross-sectional shape and form action is very close to $18 \mathrm{~min}$, This suggests that beach profile shape is basic stable 18 min after wave action, forming a rough balance of cross-sectional shape. That said in two years' return period of gravel beaches under wave profile is tending to a state of dynamic balance.

\section{Changes of Profile Model Under the Wave of 5 Years' Reproduction.}

Not recover terrain, in five years after the return period of wave with the above law, observe the beach profile morphology found that sand movement trend is basic the same that piled up, and the accumulation of the position gradually moves backward, and piled higher, in Figure 6 and Figure 7. This is mainly because the wave height increases, the frequency increases, resulting in the balance of the approximate equilibrium profile section shape before the start began to change.

\section{Changes of Profile Model Under the Wave of 10 Years' Reproduction.}

Still does not recover terrain, repeat the role of law with ten-year return period waves, it can be 
seen that as the trial, sand gradually moving back and piled higher as mentioned earlier,. Furthermore, fill sand surface also gradually become stable after a hollowed-out, its slope and beach conservation of the original slope nearly parallel. No matter how long wave effect, the hollowed out portion substantially parallel to the original surface design, test at this point, The overall height fell by about $10 \mathrm{~cm}$, actually it's close to a meter.

\section{Changes of profile Model Under the Wave of 25 Years' Reproduction.}

After designing the high water level, three times wave action once every 25 years, although the sand is still backward, but the position has been relatively stable, namely the slope to shore about 36 $\mathrm{m}$.. Bunker position on the slope move to the sea, basic stability in the slope $16 \mathrm{~m}$ to the shore or so, the deepest bunkers is about $1 \mathrm{~m}$ or so.

\section{The Beach Profile Changes after Adding Riprap Embankment.}

In this model experiment, before the side of the filling gravel adds a meter high, top width is $10 \mathrm{~m}$, front slope gradient of 1:2, back slope of 1: 2 riprap dam. Test again according to the steps before and found that the accumulation and movement of sand are with some relief relative than the one without the ripped-rock embankment, however, The final results after a comprehensive comparison, it is easy to find and two tests' results are similar, especially the filled gravel surface changes from $10 \mathrm{~m}$ to $25 \mathrm{~m}$ basically the same, so no matter set up riprap embankment or not, had a little effects on the final test results.

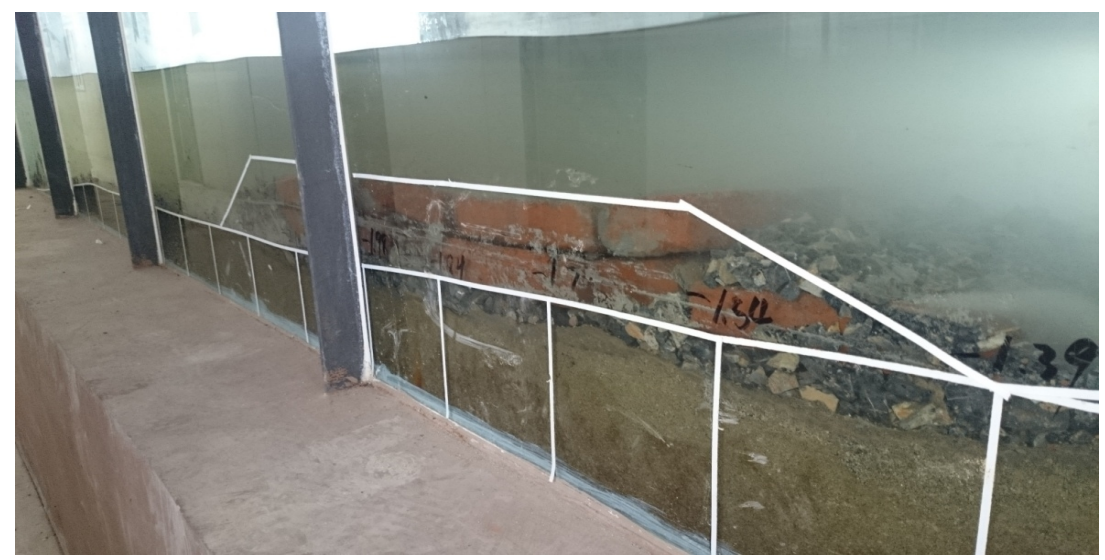

Figure 5 Ripped-rock dam

\section{Conclusion}

(1) Test results show that under the condition of design high water level, gravel beach accordance with the conditions of conservation, and under the role of local waves, its cross-section will have a greater degree of deformation, and over time will become increasingly smaller, but still difficult to achieve a very stable equilibrium. Sand source obviously goes to the shore and the pulled down toward the sea, the entire beach from shore to seaward was washed to sectional shape, and form a sediment deposit on the platform of berm. From the slope edge to the middle of the berm erosion the largest, and easy to form a bunker, while beach erosion occurs from shoulder platform to shore. The silt at the bottom of the slope is smaller than the upper, and showed a trend of decrease gradually to the sea, and was gradually decreasing towards the sea.

(2) Comparing the changes of beach profile under each return period wave action can be seen that, with the wave height, wave length, wave frequency increases, berm platform sediment deposit more and more large and always towards the shore, the degree of slope in the middle are washed more and more serious, bunker also gradually become darker. However, this test simulates the most 
unfavorable circumstances of beach, but in practice every segment of gravel beach is not necessarily the worst, so the actual case, deformation degree of the beach should be less than the test results.

(3) Comparing the changes of beach profile with and without the ripped-rock embankment can be seen that, the accumulation of sand berm platforms, the shape of slope erosion, and the movement of sand are with some relief relative than the one without the ripped-rock embankment, but comprehensive contrast two experimental results, the deformation of the beach is similar situation, little change, so in design of high water levels, the impact adding riprap embankment on coastal beach before the beach is very limited, considering the factors of economic investment benefit, there is no need to add the ripped-rock embankment before the beach.

\section{Reference}

[1] Dong Lihong, Liang Shuxiu, Sun Zhaochen. Beach maintenance theory and the progress of experimental research. Ocean Development and Management, 20125

[2] Feng Weibing, Li bing, Two-dimensional experimental study on the sandy beach profile form, Ocean bulletin, Vol. 27, No. 5 Oct. 2008.

[3] Zhuang Zhenye, Yan-xiong, Liu Huixin, Bohai Sea sandy shore beach erosion and maintenance, Introduction of Marine geology, Vol. 29, No. 2.

[4] Zhu Jinlong, Shi Bing. Research on the beach maintenance effect of near shore artificial sand bar . China Ocean University, 43 (5) 100-106, may 2013.

[5] Ma Guizhi, Discussion of corresponding wave period designed of the calculation method. [M] "Marine Sciences", 1988 (04).

[6] Liu Xiujun, Wang Yonghong. The study of the sectional process changes after maintenance. Introduction of Marine Geology, Vol. 29, No.2.

[7] Sheng Jianping, Wang Meifen, Discussion of numerical simulation of coast underwater sectional evolution, [J]. Journal of coastal engineering, 1983, 2 (1): 46-59.

[8] Li Zhiqiang, Chen Zishen Discuss of several typical beach equilibrium profile model parameters significance [J] "Waterway and Harbor", 2008, Section 4 (4): 233-238. 